\title{
Doppler echocardiography after anatomical correction of transposition of the great arteries
}

\author{
JOHN L GIBBS, ^ SHAKEEL A QURESHI, LESLEY GRIEVE, CAROLE WEBB, \\ ROSEMARY RADLEY SMITH, MAGDI H YACOUB \\ From ${ }^{\star}$ the Non Invasive Heart Unit, Killingbeck Hospital, Leeds, West Yorkshire; and Harefield Hospital, \\ Middlesex
}

SUMMARY Nineteen patients who had anatomical correction of transposition of the great arteries between the ages of one week and 10 years were investigated by pulsed and continuous wave Doppler echocardiography 1-98 months after operation. Peak blood flow velocities across the atrioventricular valves were significantly higher than normal, but no pathological regurgitation was seen. Systolic aortic velocities were normal in all but one patient, but mild aortic regurgitation was detected in ten. Increased flow velocities either at pulmonary valve level, at the pulmonary artery bifurcation, or in the left pulmonary artery were detected in 14 patients, the maximum calculated pressure drop being $36 \mathrm{~mm} \mathrm{Hg}$. Adequate Doppler sampling of the right pulmonary artery was not achieved in any of the cases, and sampling of the left pulmonary artery was possible in only ten. The principal limitation of the Doppler ultrasound method in this study was the inability to obtain flow velocities from the branch pulmonary arteries in most patients.

Doppler echocardiography provides valuable information after the arterial switch operation and may reduce the need for repeat cardiac catheterisation.

Surgical correction of transposition of the great arteries at arterial level is becoming a more widely accepted alternative to intra-atrial repair and has been the operation of choice at Harefield Hospital since 1976. At present repeat cardiac catheterisation is needed to assess the haemodynamic results of anatomical correction. The combination of cross sectional and Doppler echocardiography has not previously been evaluated in the postoperative assessment of the arterial switch operation, but could be a non-invasive means of obtaining both anatomical and haemodynamic information in these patients. This study was performed to assess the value and limitations of Doppler echocardiography after anatomical correction of transposition of the great arteries.

Requests for reprints to Dr John L Gibbs, The Non Invasive Heart Unit, Killingbeck Hospital, York Road, Leeds LS14 6UQ, West Yorkshire.

Accepted for publication 26 March 1986

\section{Patients and methods}

Nineteen patients who had anatomical correction of transposition of the great arteries between the ages of one week and 10 years (mean 13 months) were studied by pulsed and continuous wave Doppler echocardiography 1-98 months (mean 43 months) after operation. Ten patients had single stage and nine two stage correction as described elsewhere. ${ }^{12}$ In nine patients direct anastomosis of the pulmonary artery had been performed by means of the manoeuvre described by Lecompte et al. ${ }^{3}$ In 10 patients dura mater, Dacron, or calf pericardium were used to augment the pulmonary artery.

All the patients were symptom free at the time of investigation and 18 of the 19 were taking no medication. Eleven had systolic ejection murmurs audible in the pulmonary area, two had systolic murmurs at the lower left sternal edge, and two had clinical signs of mild aortic regurgitation.

Cross sectional and Doppler echocardiography were performed with $5 \mathrm{MHz}, 3.5 \mathrm{MHz}$, or $2.25 \mathrm{MHz}$ transducers. Blood flow velocities across the atrio- 


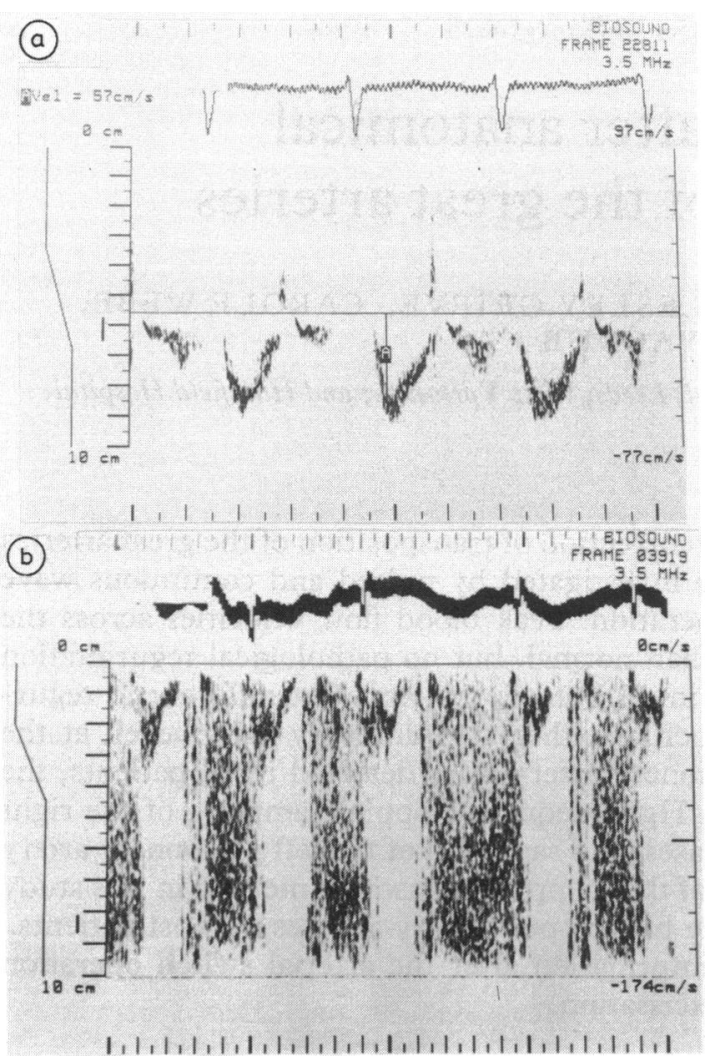

Fig. 1 Left ventricular outflow tract velocities $(a)$ in a patient with no evidence of aortic regurgitation and $(b)$ in a patient with a high velocity regurgitant jet seen in diastole. This feature was found in 10 patients.

ventricular and aortic valves were measured by means of pulsed Doppler ultrasound with simultaneous imaging (Biosound); both atria and the left ventricular outflow tract were sampled for regurgitant jets (Fig. 1). Velocities in the ascending aorta were measured from the suprasternal notch (Fig. 2) by means of both a specially designed transducer with an offset scanning plane and a $2 \mathrm{MHz}$ dedicated continuous wave transducer. Peak blood flow velocities across the atrioventricular valves and the ratio of peak velocities of the late (a wave) and early (e wave) phases of ventricular filling were recorded from an apical transducer position. Pulmonary artery flow was sampled immediately distal to the pulmonary valve, immediately proximal to the bifurcation, and where possible distal to the bifurcation. Parasternal, subxiphoid, and apical transducer positions were used to assess pulmonary artery flow velocities; the apical position was the most useful for obtaining satisfactory alignment with left pulmonary artery flow
(Fig. 3). In cases where aliasing occurred, a lower frequency transducer was selected to enable detection of peak velocity. In all cases the audio signal was used to align the Doppler ultrasound beam as closely as possible with the direction of blood flow. All measurements of velocity were taken as the modal peak of the velocity envelope, as described by Wilson and colleagues in their study of normal subjects. ${ }^{4}$

Peak pressure drops were calculated from peak velocity by the modified Bernoulli equation. In cases where aortic regurgitation was detected in the left ventricular outflow tract, diastolic reversal of flow in the ascending aorta was also sought. When possible the aortic regurgitant fraction was measured by computer assisted integration of the forward and reversed time/velocity envelopes according to the technique of Goldberg and Allen, ${ }^{5}$ by means of purpose designed software for the Apple IIe computer (Biodata Consulting, California). All measurements are expressed as an average of at least three cardiac cycles.

\section{STATISTICAL METHODS}

Unpaired $t$ tests were used to compare peak velocities with values taken from a series of 110 normal subjects. $^{4}$

\section{Results}

Cross sectional echocardiography showed that all the patients had right and left ventricles that were contracting well. All four valves appeared to be normal in all patients and no sites of obstruction to flow were identified by cross sectional echocardiography alone.

\section{ATRIOVENTRICULAR VALVES}

Peak blood flow velocities across both right and left

Table 1 Peak blood flow velocities across the mitral and tricuspid valves. There were significant differences between values measured after the arterial switch operation and those in normal subjects

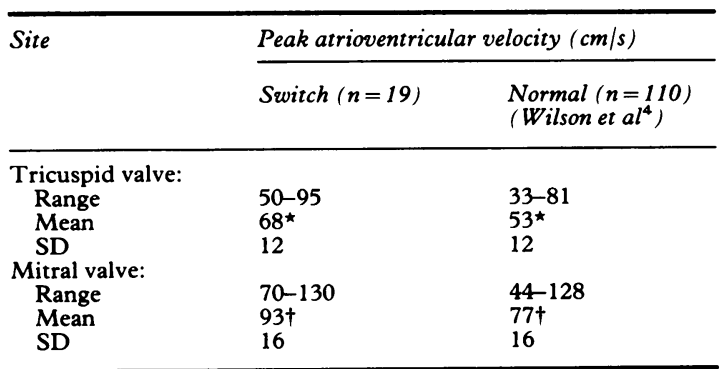

${ }^{\star} \mathrm{p}<0.01 ;+\mathrm{p}<0.02$. 

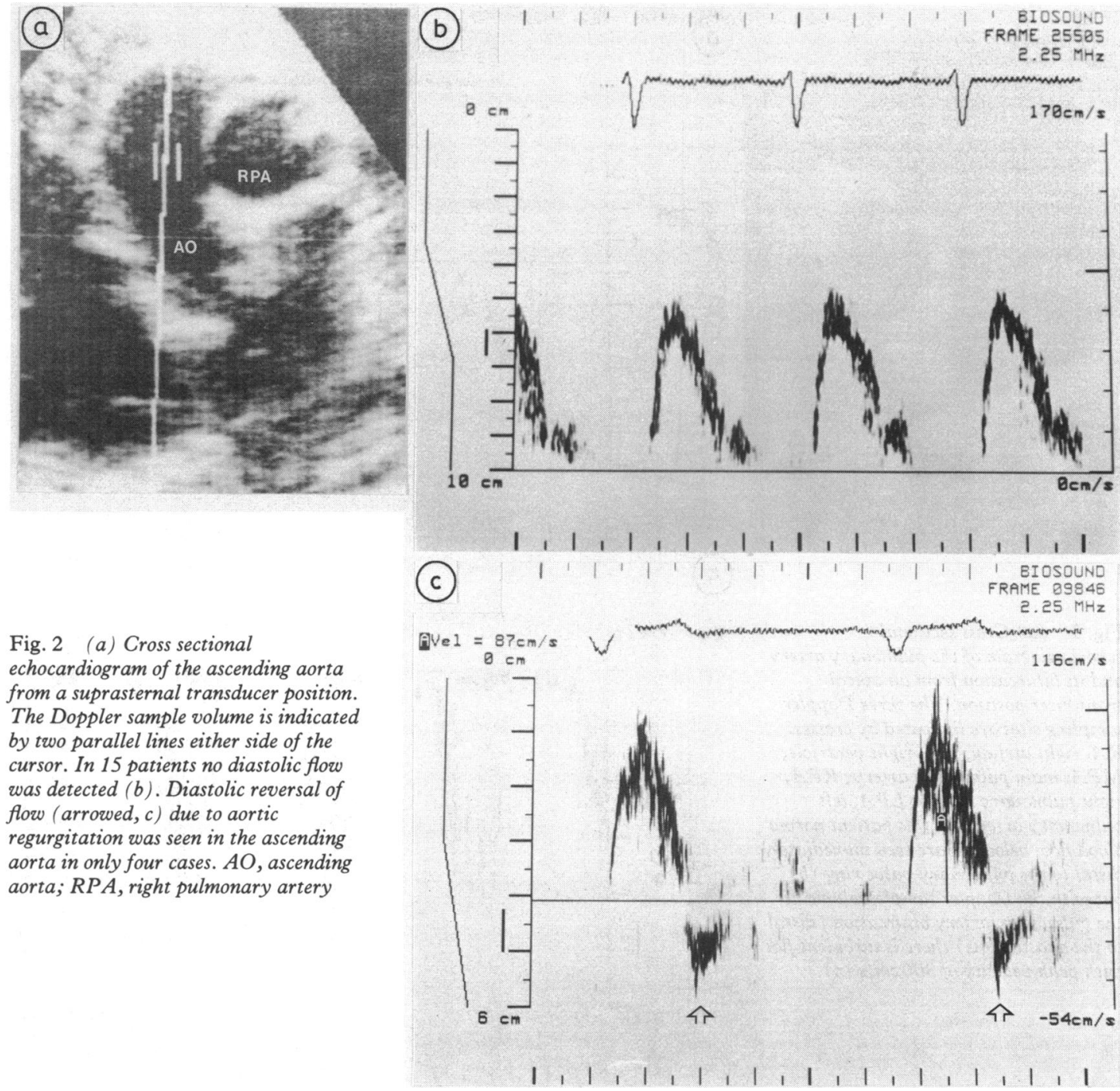

Fig. 2 (a) Cross sectional echocardiogram of the ascending aorta from a suprasternal transducer position. The Doppler sample volume is indicated by two parallel lines either side of the cursor. In 15 patients no diastolic flow was detected $(b)$. Diastolic reversal of flow (arrowed, c) due to aortic regurgitation was seen in the ascending aorta in only four cases. $A O$, ascending aorta; $R P A$, right pulmonary artery

atrioventricular valves were significantly higher (Table 1) than those reported in normal subjects. ${ }^{4}$ The mean ratio (SD) of peak a wave to e wave velocities across the mitral valve was $0.53(0.13)$ (range $0.24-0.68)$ and for the tricuspid valve it was 0.67 $(0.17)$ (range 0.29-0.92). No mitral regurgitation and only trivial early systolic tricuspid regurgitant jets (as seen in normal subjects) were detected in six cases.

\section{PULMONARY ARTERY}

Three patients had slightly raised pulmonary artery velocities immediately distal to the pulmonary valve, with calculated pressure drops of between 10 and 12 $\mathrm{mm} \mathrm{Hg}$. Doppler ultrasonography detected pressure drops of between 12 and $36 \mathrm{~mm} \mathrm{Hg}$ at the site of the main pulmonary artery anastomosis in nine patients (four after the Lecompte manoeuvre, three with Dacron conduits, and two with pericardial augmentation alone). In two further patients pressure drops of $25 \mathrm{mg} \mathrm{Hg}$ were detected between the right ventricular outflow and pulmonary artery bifurcation, but we could not be certain whether the high flow velocity originated at valve level or at the anastomotic site in the main pulmonary artery. In one patient with a $25 \mathrm{~mm} \mathrm{Hg}$ pressure drop at the anastomotic site, an additional gradient of $11 \mathrm{~mm} \mathrm{Hg}$ at the origin of the left pulmonary artery was detected. Doppler echocardiographic examination of the left pulmonary artery was possible in 10 of the 19 

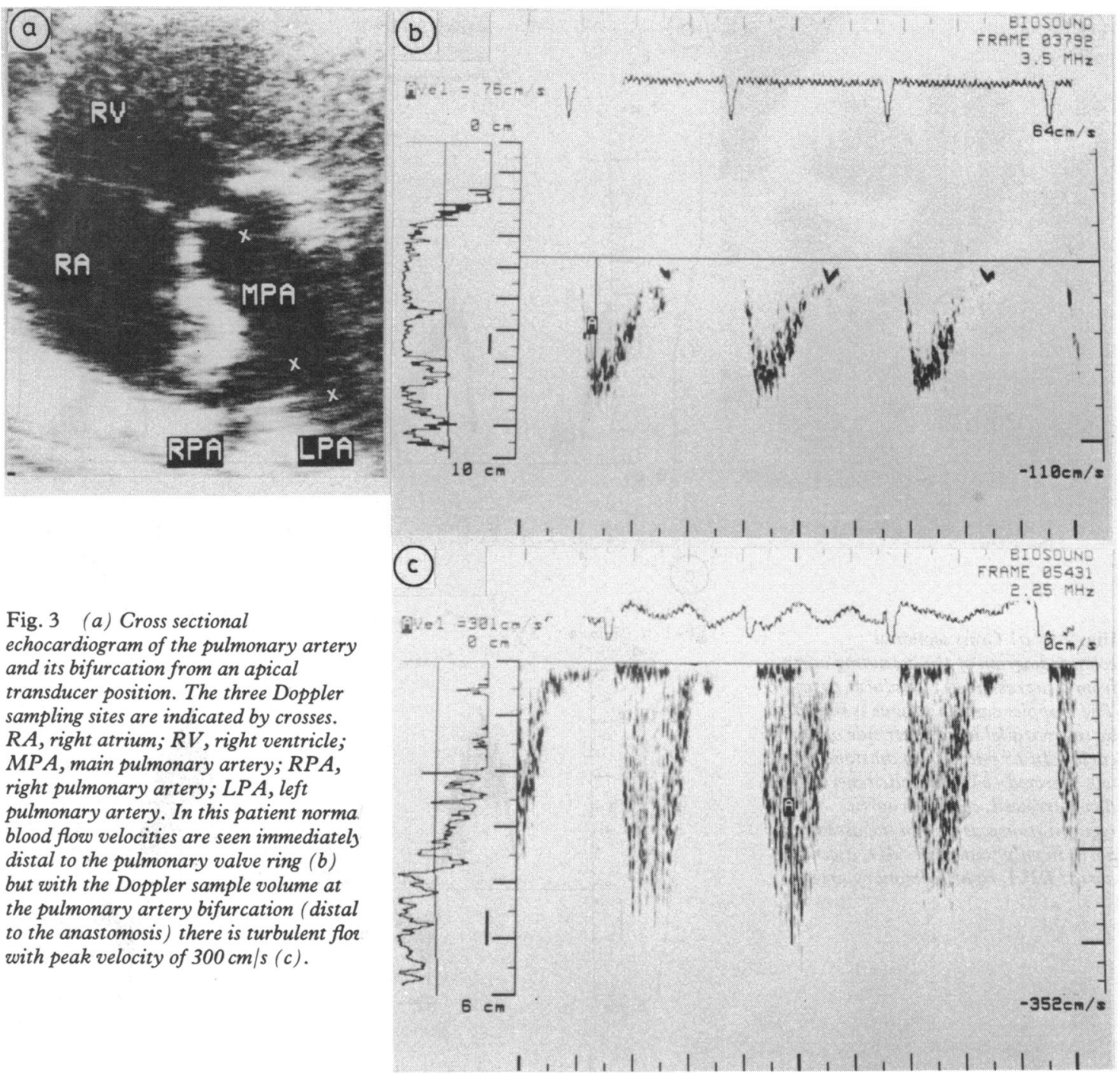

Fig. 3 (a) Cross sectional echocardiogram of the pulmonary artery and its bifurcation from an apical transducer position. The three Doppler sampling sites are indicated by crosses. $R A$, right atrium; $R V$, right ventricle; $M P A$, main pulmonary artery; $R P A$, right pulmonary artery; $L P A$, left pulmonary artery. In this patient norma. blood flow velocities are seen immediately distal to the pulmonary valve ring (b) but with the Doppler sample volume at the pulmonary artery bifurcation (distal to the anastomosis) there is turbulent flor with peak velocity of $300 \mathrm{~cm} / \mathrm{s}(\mathrm{c})$.

patients, but the right pulmonary artery was difficult to image in all cases and no reliable recordings were

Table 2 The occurrence of high pulmonary flow velocities detected by Doppler echocardiography and expressed as calculated pressure drop. In two patients it was difficult to determine whether the high flow velocity had a valvar or anastomotic origin

\begin{tabular}{lll}
\hline Site & No & Pressure drops $(\mathrm{mm} \mathrm{Hg})$ \\
\hline PV & 3 & $10-12$ \\
MPA & 9 & $12-36$ \\
?PV ?MPA & 2 & 25 \\
LPA & 1 & 11
\end{tabular}

PV, pulmonary valve; MPA, main pulmonary artery; LPA, left pulmonary artery; $N$, number of stenoses detected. obtained from this site. Pulmonary artery flow velocities were normal in the remaining five patients. Table 2 summarises Doppler findings in the pulmonary artery.

AORTIC VALVE

Peak aortic velocities (range $70-220 \mathrm{~cm} / \mathrm{s}$, mean (SD) 97 (16)) were within the normal range $(76-155 \mathrm{~cm} / \mathrm{s}$, mean $104(19))$ in all but one case (with previously diagnosed mild supravalvar aortic stenosis) in whom a peak pressure drop of $19 \mathrm{~mm} \mathrm{Hg}$ was detected with no regurgitation.

Aortic regurgitant jets in the left ventricular outflow tract were detected in 10 of the 19 patients. In six of these no diastolic flow reversal was

ত


detectable in the ascending aorta, implying that the regurgitation was haemodynamically unimportant. In the remaining four cases varying degrees of diastolic flow reversal were detected in the ascending aorta. Regurgitant fractions calculated by Doppler were $17 \%, 19 \%$, and $11 \%$ in three of these, and in one case the velocity trace was of insufficient quality for calculation of the regurgitant fraction.

\section{Discussion}

While surgical mortality for the arterial switch procedure at Harefield is approximately the same as for intra-atrial repair, ${ }^{6}$ there is limited information available on late follow up after anatomical correction. Reported complications have included transient mitral regurgitation, ${ }^{7}$ mild aortic regurgitation $^{89}$ and supravalvar pulmonary stenosis at the site of anastomosis. ${ }^{10}$ Prosthetic tubes used in the pulmonary artery anastomosis may also become obstructive, particularly when they are placed to the right rather than to the left of the aorta. ${ }^{10}$

\section{PULMONARY ARTERIAL FINDINGS}

Stenosis at the origin of branch pulmonary arteries after the arterial switch procedure has not been described previously; it was detected by Doppler ultrasound in one of our patients in whom the Lecompte manoeuvre had been used. It is possible that obstruction at this level may be produced by kinking as the main pulmonary artery is placed in its new anterior position.

In this study Doppler echocardiography appeared to be capable of identifying the site of origin of increased flow velocity in most instances, but in two cases exact localisation proved difficult. It was possible to investigate the left pulmonary artery in over half the subjects. We did, however, fail to detect branch pulmonary artery stenosis which had been found at previous cardiac catheterisation in three cases (one in the left and two in the right pulmonary artery; one present preoperatively and two after the Lecompte manoeuvre). We therefore recommend caution in the negative interpretation of Doppler findings in patients who are known to have had branch pulmonary artery stenosis preoperatively, or those in whom the Lecompte manoeuvre has been used.

SYSTEMIC ARTERIAL FINDINGS

Mild aortic stenosis at a supravalvar level was detected in only one of our patients and none had pressure drops detectable across the aortic valve.

Doppler echocardiography is a sensitive means of detecting aortic regurgitation, ${ }^{1-13}$ and in the absence of aortic stenosis the method used to quan- titate the severity of regurgitation has been reported to provide reliable estimates of aortic regurgitant fractions. ${ }^{5}$ In this study aortic regurgitant jets were detected in approximately half the patients. We found aortic regurgitation sufficient to produce detectable diastolic reversal of flow in the ascending aorta in only four of the 10 patients with regurgitant jets and the maximum regurgitant fraction detected by Doppler was $19 \%$. It has been suggested that aortic regurgitation after the arterial switch operation does not progress. ${ }^{9}$ Doppler echocardiography is readily repeatable and may provide a valuable non-invasive means of serially assessing the presence and severity of aortic valve incompetence.

\section{TRICUSPID AND MITRAL FLOW}

The importance of the finding of increased peak velocities across the mitral and tricuspid valves is uncertain. Possible causes of high velocities include valve stenosis, valve incompetence, and other causes of increased blood flow. ${ }^{14}$ No evidence of atrioventricular valve stenosis or pathological regurgitation was found in any patient and it seems unlikely that cardiac output after operation will be higher than it is in normal subjects. Transmitral blood flow velocities reflect diastolic function of the left ventricle ${ }^{15}$ and both peak mitral blood flow velocity and the ratio of the late (a wave) and early (e wave) velocity peaks may be increased in the presence of abnormalities of left ventricular function. ${ }^{16}$ Kitabatake and colleagues have reported a normal mitral a:e wave velocity ratio of 0.64 (SD 0.18 ) in a series of 18 patients ${ }^{16}$; the mean ratio in our patients was $0.53(0.13)$. However, Kitabatake's values were those of an adult population and may not be suitable for comparison with those of children.

Left ventricular end diastolic and end systolic volumes may be increased in the early postoperative months after the switch operation, ${ }^{17}$ but both right and left ventricular end diastolic pressures and ejection fractions have been found to be normal with longer follow up. ${ }^{1819}$ None the less, some patients may have abnormal indices of left ventricular stiffness ${ }^{20}$ and the shape of the left ventricle appears more globular than normal up to four years after operation. ${ }^{18}$ These geometric changes may cause some variation from normal in ventricular compliance, and this might explain the increased atrioventricular blood flow velocities. Repeat Doppler studies at later follow up are needed to determine whether atrioventricular flow velocities in this group of patients change with time.

\section{Conclusions}

The combination of Doppler and cross sectional 
echocardiography enables considerably more information to be obtained after the arterial switch operation than does echocardiography alone. Atrioventricular peak blood flow velocities in the early years after anatomical correction are higher than normal, possibly reflecting mild abnormalities in ventricular compliance. Doppler echocardiography enables detection and quantification of aortic regurgitation and assessment of severity and localisation of pulmonary arterial obstruction in most cases. The technique is less reliable in the detection of stenosis at the origins of the branch pulmonary arteries, which may occur in those patients in whom the Lecompte manoeuvre has been used for anastomosis of the pulmonary artery.

We thank Mrs Wilmar Dean for her administrative assistance.

Dr J L Gibbs is supported by the National Heart Research Fund.

\section{References}

1 Yacoub MH, Radley Smith R, McLaurin R. Two stage operation for anatomical correction of transposition of the great arteries with intact ventricular septum. Lancet 1977; 1: 1275-8.

2 Yacoub $\mathrm{MH}$. Anatomic correction of transposition of the great arteries: surgical technique. Pediatr Cardiol 1983; 4: 61-6.

3 Lecompte Y, Zannini L, Hazan E, et al. Anatomical correction of transposition of the great arteries: a new technique without use of prosthetic conduit. $\mathcal{f}$ Thorac Cardiovasc Surg 1981; 82: 629-31.

4 Wilson N, Goldberg SJ, Dickinson DF, Scott O. Normal intracardiac and great artery blood velocity measurements by pulsed Doppler echocardiography. Br Heart F 1985; 53: 451-8.

5 Goldberg SJ, Allen HD. Quantitative assessment by Doppler echocardiography of pulmonary or aortic regurgitation. Am f Cardiol 1985; 56: 131-5.

6 Yacoub MH, Radley-Smith R. Venous versus arterial switch for repair of transposition of the great arteries. Pediatr Cardiol 1983; 4: 151-8.

7 Bernhard A, Yacoub M, Regensburger D, et al. Further experience with the two-stage anatomic correction of simple transposition of the great arteries. $f$ Thorac Cardiovasc Surg 1981; 29: 138-42.

8 Yacoub M, Bernhard A, Lange P, et al. Clinical and haemodynamic results of the two stage anatomic correction of simple transposition of the great arteries. Circulation 1980; 62: 190-6.
9 Williams WG, Trusler GA, Freedom RM, Olley PM, Duncan WJ, Rowe RD. Results of arterial repair of transposition: the Toronto experience. Pediatr Cardiol 1983; 4: 99-104.

10 Yacoub MH, Bernhard A, Radley-Smith R, Lange P, Sievers H, Heintzen P. Supravalvular pulmonary stenosis after anatomic correction of transposition of the great arteries: causes and prevention. Circulation 1982; 66: 193-7.

11 Quinones MA, Young JB, Waggoner AD, Ostojic MC, Ribeiro LGT, Miller RR. Assessment of pulsed Doppler echocardiography in detection and quantification of aortic and mitral regurgitation. $\mathrm{Br}$ Heart $\mathcal{F} 1980$; 44: 612-20.

12 Esper RJ. Detection of mild aortic regurgitation by range gated pulsed Doppler echocardiography. Am $\mathcal{f}$ Cardiol 1982; 50: 1037-43.

13 Ciobanu M, Abbasi AS, Allen M, Hermer A, Spellberg R. Pulsed Doppler echocardiography in the diagnosis and estimation of severity of aortic insufficiency. $A m \mathcal{Y}$ Cardiol 1982; 49: 339-43.

14 Goldberg SJ, Wilson N, Dickinson DF. Increased blood flow velocities in the heart and great vessels of patients with congenital heart disease. An assessment of their significance in the absence of valvar stenosis. $\mathrm{Br}$ Heart $\mathcal{f}$ 1985; 53: 640-4.

15 Rokey R, Kuo LC, Zoghbi WA, Limacher MC, Quinones MA. Determination of parameters of left ventricular diastolic filling with pulsed Doppler echocardiography: comparison with cineangiography. Circulation 1985; 71: 543-50.

16 Kitabatake A, Inoue $M$, Asao $M$, et al. Transmitral blood flow reflecting diastolic behaviour of the left ventricle in health and disease. A study by pulsed Doppler technique. Ipn Circ F 1982; 46: 92-102.

17 Heintzen PH, Lange PE, Wessel A, Radley Smith R, Bernhard A, Yacoub MH. Angiocardiographic and echocardiographic evaluation of ventricular geometry and function before and after two stage correction of complete transposition of the great arteries with intact ventricular septum. Pediatr Cardiol 1983; 4: 123-30.

18 Arensman FW, Radley-Smith R, Yacoub MH, et al. Catheter evaluation of left ventricular shape and function one or more years after anatomic correction of transposition of the great arteries. Am $\mathcal{F}$ Cardiol 1983; 52: 1079-83.

19 Lange PE, Onnasch DGW, Stephan A, et al. Two stage anatomic correction of complete transposition of the great arteries: ventricular volumes and muscle mass. Herz 1981; 6: 336-43.

20 Hausdorf G, Gravinghoff L, Sieg K, Keck E, Radley Smith R, Yacoub MH. Left ventricular performance after anatomic correction of d-transposition of the great arteries [Abstract]. F Am Coll Cardiol 1985; 5: 479. 